\title{
Coping with traumatic memories: Second World War veterans' experiences of social support in relation to the narrative coherence of war memories
}

\author{
KAREN J. BURNELL*, PETER G. COLEMAN† and NIGEL HUNT $\ddagger$
}

\begin{abstract}
This paper reports a qualitative study that used narrative analysis to explore how social support helps many armed-services veterans cope with traumatic memories. The analysis was carried out on two levels, that of narrative form (level of narrative coherence), argued to be indicative of reconciliation, and narrative content (themes of social support), which allowed exploration of the types of social support experienced by veterans with coherent, reconciled and incoherent narratives. Ten British male Second World War veterans were interviewed regarding their war experiences, presence of traumatic memories, and experiences of social support from comrades, family and society. Different patterns of support were qualitatively related to coherent, reconciled and incoherent narratives. Veterans with coherent narratives were no less likely to have experienced traumatic events than those with reconciled or incoherent narratives, but they reported more positive perceptions of their war experience and of the war's outcomes, more positive experiences of communication with family in later life, and more positive perceptions of societal opinion. The results are discussed in relation to how veterans can be supported by family and friends to reconcile their traumatic memories, thus to lessen the burden in later life when vital support resources may be unavailable.
\end{abstract}

KEY WORDS - narrative analysis, narrative coherence, social support, reconciliation, Second World War, veterans.

\section{Introduction}

It is well documented that social support can help armed-service veterans come to terms with traumatic memories (Solomon, Mikulincer and Avitzur I988), but how social support helps is a complex question.

* Department of Mental Health Sciences, University College London, London, UK.

$\dagger$ School of Psychology, University of Southampton, Southampton, UK.

$\$$ Institute of Work, Health and Organisations, University of Nottingham, Nottingham, UK. 
In recent years, there has been a drive to understand these social support processes (Dirkzwager, Bramsen and van der Ploeg 2003; King et al. 1998), and qualitative research has played an important role in revealing interesting themes of comradeship, family support and societal support (Burnell, Coleman and Hunt 2006 $a$; Hunt and Robbins 200I). This paper departs from most previous studies by exploring how meaning is made of experiences through narrative, and the role that social support plays in aiding or hindering this process. It is important to explore the process of making meaning through narrative because it is believed to be a natural process (Polkinghorne i988), and could be a useful clinical tool when working with war veterans.

The presence of trauma can become more problematic in later life through age-related cognitive, physical, and social network changes (Baltes and Lang 1997), which may make the management of memories or reconciliation more difficult through continued avoidance. From a clinical perspective, it is argued that veterans who manage and reconcile their traumatic memories experience fewer post-traumatic symptoms (Foa, Molner and Cashman i995). Whether it is beneficial or harmful for people to discuss their experiences is keenly debated. In particular, psychological debriefing has received much attention for there is evidence that it results in increased trauma and depressive symptoms (Rose et al. 2007; Wessely and Deahl 2003). Wessely suggested that psychological debriefing has limited efficacy because the intervention involves professionally-facilitated, singletreatment sessions rather than natural support networks such as friends and family. Conversely, Deahl argued that psychological debriefing is effective in a naturalistic context but not in a randomised-controlled trial, which is unlikely to represent the practical reality of debriefing. It has also been argued that narrative therapies are particularly useful in treating survivors of trauma (cf. narrative exposure therapy, for which see Neuner et al. 2004). These formal therapies require repeated verbalisation of traumatic memories to encourage habituation to the traumatic elements of the memory and the integration of flashbacks into the fragmented and dissociated narrative, which leads to the remission of traumatic symptoms through the creation of a more complete and coherent narrative. Once again, these therapies require professional facilitation rather than management using natural support.

\section{Traumatic memory and relation to narrative coherence}

Narrative therapies are based on the premise that individuals are in a constant process of constructing their life story or personal narrative. Whilst Butler (1963) demonstrated that people have a desire to perform 
this process in later life (defined as life review), narrative psychologists argue that this task does not occur exclusively in later life, but rather that we evaluate experiences throughout life, which allows us to understand life events and create or maintain identity through the creation of the personal narrative (McAdams 200I). As such, narrative approaches may provide a natural opportunity to reconcile or manage memories, particularly when aided by informal supporters.

The concept of the personal narrative is based on the assumption that we use story components to order life experiences, which provides structure and continuation in order to make meaning of these events (Bruner I986). The desired outcome is a coherent personal narrative in which the relationships between different elements of the story are interwoven (Linde I993), and subjective truths, interpretations, emotional evaluation, unity/integration, purpose and meaning are made explicit (Coleman I999). Traumatic events disrupt this meaning-making process because such catastrophic experiences challenge our perceptions of the world and ourselves, and consequently cannot easily be integrated into the life story because of their incongruity (Janoff-Bullman I992). Difficulty in finding meaning may explain why survivors of trauma not only experience vivid flashbacks, but also a disorganised, fragmented and incoherent narrative (Foa, Molner and Cashman I995).

As early as I9o9, Janet (Igog) noted the concurrence of a dissociated and fragmented narrative and threatening vivid flashbacks in traumatic memory, an association that has recently been supported by research into the neurobiology of memory. Brewin, Dalgleish and Joseph (I996) suggested that two types of memory associate with trauma, verbal and situational. Verbally-accessible memory (VAM) is responsible for the narrative aspect of the traumatic memory. VAM is partially integrated in autobiographical memory, which gives rise to a fragmented and dissociated narrative that can be accessed deliberately when required. Situationallyaccessible memory (SAM) is responsible for flashbacks, which are vivid memories that are triggered automatically and involuntarily and result in emotionally threatening but richly detailed memories. Brewin (200I) has argued that information in the SAM and VAM systems needs to be integrated, so that the rich detail of flashback memory completes the fragmented narrative. With this, the narrative produced by VAM will become coherent and flashbacks lose their threatening and involuntary nature.

It is natural for survivors of trauma to avoid flashbacks, but avoidance tends to result in perpetuation of the symptoms because the memory is not resolved and remains threatening (McFarlane I992). As argued by Brewin, Dalgleish and Joseph (I996), by processing and integrating memories into 
a coherent narrative form, survivors of trauma may be better able to make sense of their traumatic experiences, and these memories consequently lose their threatening nature and become reconciled (Creamer, Burgess and Pattison 1992; Zoellner, Alvarez-Conrad and Foa 2002). Over time, the trauma narrative may emerge as an explicit and integrated personal narrative (van der Kolk and Fisler i995).

\section{Narrative coherence and social support}

Whilst pre-trauma social support networks have been found to protect against the emotional sequelae of traumatic war experiences (Dirkzwager, Bramsen and van der Ploeg 2003; Kaspersen, Matthiesen and Gotestam 2003), the types of support experienced post-trauma also influence subsequent coping strategies and the management of traumatic memories (King et al. 1998). Two coping strategies that influence how veterans cope with traumatic memories have been identified: avoidance and processing (Hunt and Robbins 200I). Their identification complemented Cohen and Wills's (1985) seminal hypotheses about the buffering and main-effects of social support. Avoidance involves staying out of situations or away from people that trigger traumatic memories, a buffering hypothesis because social support is used to protect the individual from stressful situations. This coping strategy may result in the persistence of psychological distress or late-onset symptoms. Processing involves actively seeking people who will support the conscious recall of the memory, thus providing the opportunity to narrate and make meaning of traumatic memories. This exemplifies the main-effect hypothesis, which results in feelings of integration and belonging, and promotes safe and valued communication.

Hunt and Robbins (200I) investigated the mechanisms of avoidance and processing among British Second World War (WWII) and Korean War veterans. They found that the veterans processed their memories at veterans' associations with comrades of the same war or, more congenialy, with others who served with them. Family members were used as a safe haven to avoid both conversation and triggers of memories about traumatic war experiences. Research with British Falklands (Malvinas) War veterans revealed that veterans spoke more with family members than comrades, perhaps because these veterans were still serving at the time of the study and felt unable to talk to comrades (Burnell, Coleman and Hunt 2006a).

As well as individual support, societal affirmation is also thought to play a vital role in aiding reconciliation. When the dominant public narrative or discourse about a war is positive, it creates a supportive environment in which veterans feel valued for their service (Hautamäki and Coleman 
200I). This extends to the importance of collective commemoration (i.e. national remembrance days) in which veterans can reminisce safely with support. Barron, Davies and Wiggins (2008) demonstrated that collective communication provides social integration and a sense of belonging that makes processing easier for veterans. This links to the concept of social and cultural memory (Halbwachs I992; Hunt and McHale 2008), which if consistent with individual memory may enable a more coherent narrative. The social discourse may change over time in ways that may conflict with the veteran's memory of an event; social memory and individual memory may over time increasingly conflict, and veterans may find it harder to process their memories and achieve reconciliation.

These different types of support either aid or hinder processing and integration and, in turn, impact on the creation of a coherent narrative in which memories are made meaningful and explicit. Whilst it is known that both avoidance and processing are used by veterans, the specific processes that lead to coherent and incoherent narratives have not to date been investigated. This study explored the types of social support that are related to reconciliation as indicated by the level of a veteran's narrative coherence.

\section{The research design}

\section{Rationale}

A narrative approach was adopted because there is evidence that traumatic events impact on our ability to find meaning. A number of narrative analytical approaches are available. Biographical and life history approaches focus on the life story as a whole and the behaviour of the individual in the context of the socio-cultural environment (Chase 2008; Riessman 2002). Whilst these approaches provide rich case data, the current study was particularly interested in a specific life event and how meaning was then derived (or not) through social support. To understand these processes and their associations with narrative coherence, it was believed important to compare the experiences of a number of veterans. Such an approach is similar to Riessman's (1993). Riessman focused on the way the story is told rather than the content alone, and emphasised the need to understand the interactions between the personal and public narratives. Whilst this was of interest, the focus of the present study is the impact of society on individual coping, not the interactions between the individual and society. The adopted psychological approach to narrative focuses on the structure, content and function of the stories and the impact on the individual (Murray 2003), and the underlying hypothesis 
was that specific types of social support relate to how some veterans came to terms with their experiences post-war whilst others did not.

\section{The participants}

The Royal British Legion (RBL), various WWII veterans' associations and local newspapers in Hampshire, Dorset and Wiltshire in England were asked to assist with recruitment to the study. Many responded positively and published a description of the study and our invitation to participate. Several veterans responded after seeing the advertisement, and others after hearing about the study from a friend. From the veterans who agreed to participate, a convenience sample was compiled of veterans who lived in the Midlands, Devon and Cornwall, East and West Sussex, and in the Solent area (it turned out that all were recruited through the RBL and the Burma Star Association). Prior to each interview, a telephone call checked that the veteran still wished to participate. Ten male veterans, aged from 80 to 86 years (and aged i7 to 20 years during active service), gave faceto-face interviews (nine at their homes and one elsewhere). The interviews lasted one to two hours and were conducted between April and September 2005. Seven had served in the British Army, one in the Royal Navy, and two in the Royal Air Force.

\section{The interviews}

A semi-structured interview schedule developed by Burnell, Coleman and Hunt (2006a) was used. It has eight questions on the respondent's military record, war experience, social support, perceptions of media representations, and the importance of commemoration. The schedule was loosely followed and all questions were framed to be neutral and non-judgemental (Smith 1995), in the hope that the veterans felt free to share their opinions (Wilkinson, Joffe and Yardley 2004). All interviews were transcribed by the first author and, after transcription a two-level analysis was conducted. ${ }^{1}$

\section{Data analysis: the focus on narrative form}

Narrative form concerns the way in which a story is told rather than its content. In this study, the analysis focused on narrative coherence as an indication of reconciliation. A coherent narrative was defined as one that is structured, affectually consistent, and is fully integrated. The identification criteria focused on the important story-telling components in the orientation, structure, affect and integration of the narratives, as detailed in Table I. The criteria were influenced by narrative theory and previous clinical research, particularly those proposed by Baerger and McAdams 
T A в L E I. The criteria of narrative coherence

\begin{tabular}{|c|c|c|}
\hline Elements & & Coding criteria and definitions \\
\hline Orientation $(\mathrm{O})$ & $\begin{array}{l}\mathrm{O}_{1} \\
\mathrm{O}_{2}\end{array}$ & $\begin{array}{l}\text { Introduction of main characters (scene setting). } \\
\text { Temporal, social, historical and personal context. }\end{array}$ \\
\hline \multirow[t]{2}{*}{ Structure (S) } & $\mathrm{S}_{3 \mathrm{a}}$ & $\begin{array}{l}\text { Structural elements of an episodic system presented with causal and } \\
\text { temporal coherence (does not include contradictions). Structural } \\
\text { elements include an initiating event, an internal response, an } \\
\text { attempt and a consequence. }\end{array}$ \\
\hline & $\mathrm{S}_{3} \mathrm{~b}$ & $\begin{array}{l}\text { Explicit recognition of temporal coherence, e.g. 'I've jumped the } \\
\text { gun/where was I?' Explicit recognition of storytelling. }\end{array}$ \\
\hline \multirow[t]{2}{*}{ Affect (A) } & $\mathrm{A}_{4}$ & $\begin{array}{l}\text { Past or present emotional evaluation of what described events mean } \\
\text { to the narrator communicated through explicit statements of } \\
\text { emotion. }\end{array}$ \\
\hline & $\mathrm{A}_{5}$ & Consistency of verbal and non-verbal content within a meaning unit. \\
\hline \multirow[t]{3}{*}{ Integration (I) } & I6 & $\begin{array}{l}\text { Meaning of events/experiences is expressed within the context of } \\
\text { the larger story, including a coherent explicit or implicit theme } \\
\text { linking all the events. }\end{array}$ \\
\hline & $\mathrm{I}_{7}$ & $\begin{array}{l}\text { Contradictions between events or the narrator's personality traits } \\
\text { or values, emotional evaluation, or changes in attitudes are } \\
\text { acknowledged and explained in a causally coherent manner. }\end{array}$ \\
\hline & I8 & $\begin{array}{l}\text { Presence of fragmentation of the narrative defined as broken speech } \\
\text { and unfinished sentences. Also, defined as incongruent } \\
\text { information within the context of the larger narrative. Unless } \\
\text { otherwise stated the narrative is fluid. }\end{array}$ \\
\hline
\end{tabular}

(1999), Habermas and Bluck (2000) and Androutsopoulou et al. (2004), which were adapted to ensure their applicability to war trauma and to fragmented and disorganised narratives (Burnell, Hunt and Coleman $2006 b)$.

The orientation and structural criteria identified the basic story-telling components common to many of the narratives. Consistency of affect at the implicit/explicit and verbal/non-verbal levels was also included, along with integration components such as the presence of a uniting theme, absence of contradictions, and absence of fragmentation. Consistent and congruent affect reflects resolution and the ability to convey the emotionality of an event, whilst integration indicates that the person had found meaning in their war experiences and understood their impact on their overall life story. Together, affect and the integration criteria reflect emotional and thematic evaluations of lived experience.

The narratives were coded as coherent, reconciled and incoherent using the criteria. In order to be considered a coherent narrative, criterion I8 did not apply but all other indicative criteria were present (see Table I). If the narrative was coded as coherent but the veteran indicated that there had been traumatic symptoms in the past but no longer, the narrative was regarded as reconciled. If a criterion was absent or I8 was present, the 
narrative was recognised as incoherent, because without narrative orientation and structure it may be more difficult to engage a supportive audience willing to listen and to support the emotional evaluation and integration that are vital for meaning making (Linde 1993). Using the specified procedure, the veterans' narratives were categorised into coherent (three cases), reconciled (two) and incoherent (five).

\section{Narrative content}

The content analysis of the veterans' narratives focused on the types of social support that were sought and provided during and after their years of service. Thematic analysis was carried out in a form consistent with narrative analysis. Murray (2003) argued that whilst thematic analysis decontextualises content to find patterns of interest across individuals, narrative analysis searches for common themes across narratives, whilst maintaining the context of the personal narrative. The units of analysis were either whole sentences or paragraphs, and for each the contained themes and narrative patterns were identified (Joffe and Yardley 2004). Both manifest (directly observable) and latent (requiring interpretation) themes were noted. The initially identified themes were adopted from previous research on WWII narratives (Burnell, Coleman and Hunt $2006 a$ ) and applied deductively, but subsequently inductively identified (or emergent) themes were also specified. After the first coding, one interview was revisited and inductive themes were coded into exclusive categories; that is, only one code was applied to each unit of analysis, and the articulated words were used to name the category. These categories were then applied to the remaining interviews. As the analysis proceeded, the original categories became conceptual and abstract but not decontextualised, and certain themes were spliced and others aggregated into one theme. Two of the authors independently assessed the credibility and application of both the inductive and deductive themes and the narrative coherence criteria. The resulting analysis provided a meaningful way of understanding the veterans' social support experiences.

The themes identified three aspects of social support that related to perceptions of war experience: comradeship and communication, family support and communication, and societal support and opinion. Interesting differences were found in these themes as between veterans with coherent, reconciled and incoherent narratives. The findings are presented for each of these narrative groups and illustrated with selected quotations using fictitious initials (for the transcription conventions, see Table 2). To aid interpretations, summary accounts of the participants' war experience are also provided in Table 3 . 
T A в L E 2. The transcription conventions

\begin{tabular}{|c|c|c|}
\hline Symbol & Convention & Description \\
\hline$\ldots$ & Standard ellipsis & Pause in the speech of participant \\
\hline / & Forward slash & Elision of material \\
\hline$(t e x t)$ & $\begin{array}{l}\text { Brackets with content } \\
\text { italicised }\end{array}$ & $\begin{array}{l}\text { First use to denote anonymised information e.g. (town). } \\
\text { Second use following colloquial use of words or grammar, } \\
\text { e.g. (sic) }\end{array}$ \\
\hline$($ text $)$ & $\begin{array}{l}\text { Brackets with content } \\
\text { in standard font }\end{array}$ & $\begin{array}{l}\text { First use to denote interview events e.g. (laughs). } \\
\text { Second use to provide clarifying information for the reader, } \\
\text { e.g. (Tony Blair, British Prime Minister) }\end{array}$ \\
\hline [text] & Square brackets & Contains interviewer's questions \\
\hline
\end{tabular}

\section{The coherent narratives}

\section{Perceptions of war experience}

The veterans with coherent narratives perceived their war experience as positive, albeit with some intense moments, but an episode that had benefited their post-war life. As LI said:

and it occurs to me ... that in fact what we were doing ... was ... a long-term industry-based sandwich course (laughs) ... with much longer slices of practical experience (laughs) and rather more dangerous practical experience ... but ... I was impressed by the way in which my ... naval career ... was handled.

An important theme that emerged from the interviews was that of the factors that were perceived to protect against the traumas of war. For QC, religion allowed him to cope with his war experiences. He explained:

I was a ... committed Christian at the time ... and ... so ... it ... things didn't get me down/I was very fortunate.

\section{Comradeship}

Whilst the comradeship during their years of service was seen positively, and the veterans reported frequent communication about the events of war, exchanges about trauma were infrequent or actively avoided. As LI explained:

if one spoke about it ... it was with the usual black or gallows humour that arises in these situations ... we ... we hadn't heard of ... post-traumatic stress ... the two expressions in use were that you were 'shit-scared'.. and if you were shitscared often enough you became 'bomb happy'. 
T А в L E 3. The participants' armed-service experiences

\begin{tabular}{|c|c|}
\hline Participant & War experiences and sequelae \\
\hline \multicolumn{2}{|c|}{ Veterans with coherent narratives: } \\
\hline LI & $\begin{array}{l}84 \text { years-old. Joined the Royal Navy in I94I at the age of 20, serving until I946. } \\
\text { HR: Lieutenant. Served on landing craft. TW: W Europe, commando raids in } \\
\text { Norway, and the Sicilian, Italian and D-Day beach landings. VA member. }\end{array}$ \\
\hline QC & $\begin{array}{l}85 \text { years. Joined the Army in I940 at the age of } 20 \text {, serving until I946. HR: } \\
\text { Lieutenant. Served as a Chindit and infantry officer. TW: the Middle East and } \\
\text { Burma. VA member. }\end{array}$ \\
\hline $\mathrm{KG}$ & $\begin{array}{l}\text { 8I years. Joined the Royal Air Force in I94I at the age of I8, serving until I946. } \\
\text { HR: Warrant Officer. Specialised as a bomber. Based in Britain. TW: Germany } \\
\text { and German-occupied Europe. VA member. }\end{array}$ \\
\hline \multicolumn{2}{|c|}{ Veterans with reconciled narratives: } \\
\hline FNK & $\begin{array}{l}86 \text { years. Joined the Army in I939 at the age of I9, serving until I946. HR: Captain. } \\
\text { Pilot in the Royal Artillery. TW: Burma and Malaya, and Northern Ireland during } \\
\text { I939-4I. Married during the war, but later divorced and remarried. Published his } \\
\text { autobiography in I997. VA member. }\end{array}$ \\
\hline ET & $\begin{array}{l}\text { 8o years. Joined the Army in I } 943 \text { at the age of I8, serving until I947. HR: Staff } \\
\text { Sergeant. Served with the Royal Signals in the Burma Campaign. Immediately } \\
\text { after being demobbed, emigrated to Canada. VA member. His wife was present } \\
\text { during the interview. }\end{array}$ \\
\hline \multicolumn{2}{|c|}{ Veterans with incoherent narratives: } \\
\hline $\mathrm{EU}$ & $\begin{array}{l}86 \text { years-old. Joined the Army in I } 939 \text { at the age of 20, serving until I } 957 \text { in the } \\
\text { Territorial Army. HR: Major. Served as an operator in the Royal Signals in } \\
\text { South-East Asia. He was single during service, but married the year of return. } \\
\text { VA member. }\end{array}$ \\
\hline JI & $\begin{array}{l}\text { 84 years. Joined the Army in } 1939 \text { at the age of I7, serving until I946. HR: Captain. } \\
\text { Served as a flail tank commander in various army regiments. TW: NW Europe, } \\
\text { where participated in the D-Day Normandy beach landings. In I99I, published his } \\
\text { autobiography. VA member. }\end{array}$ \\
\hline WU & $\begin{array}{l}82 \text { years. Joined the Army in I94I at the age of I7, serving until I960. HR: Warrant } \\
\text { Officer. TW: W Europe, where he participated in all the European war campaigns. } \\
\text { VA member. }\end{array}$ \\
\hline $\mathrm{XT}$ & $\begin{array}{l}82 \text { years. Joined the Royal Air Force in I940 at the age of I8, serving until I946. } \\
\text { HR: Warrant Officer. Specialised as a wireless operator and air gunner. Based in } \\
\text { Britain and tasked with searching for U-Boats. VA member. }\end{array}$ \\
\hline $\mathrm{BD}$ & $\begin{array}{l}\text { 80 years. Joined the Army in I943 at the age of I7, serving until I947. HR: Sergeant. } \\
\text { Served with the Royal Signals. TW: Burma and Malaya. VA member. }\end{array}$ \\
\hline
\end{tabular}

Notes: The ages given at the beginning of each profile are those at the time of interview. HR: highest rank attained. TW: theatres of war in which served (selected locations). VA: member of a veterans' association. I. The Chindits were a special unit of the British army that fought behind enemy lines in North Burma during I943-44 (for more details see www.chindits.info).

LI also spoke with regret about not sharing war memories with other exservicemen after the years of service, and illustrated how humour was used to avoid communication. Referring to exchanges with his colleagues at a school where he taught, he said:

it was an extremely good school/with quite a big sprinkling of ... exservicemen ... who didn't ... again ... one didn't talk ... much about ... I regret that we didn't talk about it/one generally spoke about it in a jokey (sic) manner. 
Despite this lack of communication, veterans' associations were perceived as being extremely important, particularly in later life when the veterans could devote more time to meetings and reunions. $\mathrm{KC}$ explained well:

Yes ... yes it is important ... we (members of the association) were late starters ... the first ... unofficial squadron reunion we had/(was) about 22 years after the war/but the reason for that is quite simple/all our energies were devoted to our ... marriage ... and to our families ... and to bring up children/and suddenly we find the children leave the nest ... and ... we've got a bit of spare time.

\section{Family support}

Family interactions were perceived positively immediately after service and in later life. In fact, this support was seen as imperative to successful adjustment after the war. As LI reasoned:

if we shift to the question of how one coped ... post-war ... the thing that occurs to me ... is that I came out ... into what was ... and remained ... a stable ... rural ... family ... environment/if one wanted therapy ... one probably couldn't do better ... plus ... stable employment ... in a rewarding ... and very happy job.

Interestingly, whilst communication with comrades about trauma did not occur immediately after service or in later life, some veterans had always been able to raise the topic with family members. QC said, 'I was very happy to talk about them (experiences)/yes ... I'm sure that's a help/if you can get talking about it ... life gets much better', but for others, noncommunication was more common, partly because of a perception that the topic bored others. Importantly, however, there was no apparent avoidance of communication, and these veterans would talk about their experiences if asked. LI put it like this: 'I think ... yes ... we talked about the ... about my service ... but ... probably more about the ... travel aspect of it ... than anything else'.

\section{Societal support}

Positive perceptions of societal support, homecomings and communication with society were dominant themes in the narratives. For instance, QC remembered that people were 'pleased to see you ... I walked into the greengrocer's ... and she'd say ... "how's the noble Captain today?" / People were very pleased to see you'. Commemoration and remembrance were important events for the veterans, especially when the currently serving forces were present. KC explained:

we hold our Remembrance Sunday ... service there ... every year/yes ... yes...the present squadron and the ... Squadron Association ... are 
represented/it's nice ... that we have ... the present squadron in uniform ... and that completes it.

As to the media portrayal of war and its supposed consequences, the veterans' perceptions were negative, apart from LI who explained how documentaries about others' war experiences had helped him understand his own fears (a form of virtual comradeship). LI explained, 'I've actually seen on television ... a programme about the Battle of the Atlantic ... (there was) a survivor remembering what I remember ... on the beach in Sicily.

\section{The reconciled narratives}

Traumatic memories had come back to these veterans in later life, and they spontaneously attributed this to their earlier avoidance of such recollections, but importantly these veterans felt they had subsequently been reconciled. As ET explained,

you weren't encouraged to think about them in those days in fact ... I ... sitting down like this ... it's only in recent ... years ... that I've ... you know ... the memories seem to come back.

\section{Perceptions of war experience}

These veterans spoke about their war experiences in both positive and negative terms, and they were described as both enjoyable and horrific. ET recollected:

I spent a ... reasonably happy time in ... in Bangkok. ... As I say, there were plenty of people to do the work, so the shifts were ... were ... rather ... easy going./My most harrowing experience of the war, I suppose, was the repatriation of the prisoners of war because we saw them in their worst state.

Negative outcomes were also reported, in that war experience had taken several years of their young adult lives and had affected their subsequent civilian careers. FNK weighed it up like this: 'it was a good career in the end, once it got going ... but given the war and the ... difficult period afterwards ... it did take its time'. Neither ET nor FNK mentioned risk or vulnerability factors during the interviews, but unlike those with coherent narratives, nor did they refer to protective factors.

\section{Comradeship}

Comradeship was described very positively, but there was no evidence that communication about traumatic events had occurred. Both ET and FNK avoided talking to comrades during and immediately after their 
service. In FNK's following remark, the use of alcohol was mentioned and can be interpreted as aiding avoidance:

And I don't think we (comrades at University) talked much about the war ... in fact, I don't think I ever remember doing it ... we were much too concerned to meet at (name of inn) at night and ... have a few/I think we were doing it to get it out of our system really.

Similarly, even though ET was still in contact with another veteran, communication about their war experiences had been avoided. He explained, 'we both knew that we had served/but we never spoke about it ... we never spoke about it in those days'. Veterans' associations had become more important for both ET and FNK in later life as a source of positive feelings about their war experiences. Whilst communication was not specifically mentioned, one can appreciate the value of veterans' associations from FNK's remarks:

Yes (the Squadron Association was important) immediately after/in the years after the war ... I would simply go out to meet the blokes again ... and have a drink with them and, you know ... pat them on the back and feel good about it and all that sort of thing.

\section{Family support}

In terms of familial support, interactions with family members were not always positive in the immediate aftermath of the war, and avoidance was then encouraged, but as the years passed, communication began and family relations improved. FNK explained that after the war, communication was avoided because he thought that his war experience lacked meaning and importance, but this changed later in life:

I can blame myself for not wanting to talk about it ... I don't think I was exceptional in that aspect... I don't mind talking about it today/I thought I had something to talk about after a while.

\section{Societal support}

Both these veterans perceived societal support as very positive, which appeared to have helped them come to terms with their experiences. ET spoke of the importance of feeling appreciated during a remembrance service: 'it is (nice to feel appreciated) ... you ... you do feel as though ... what you did was ... maybe worth while. FNK also saw commemoration and remembrance as an important way of remembering comrades:

(Commemoration days) are very important because of ... the chaps who died in Burma, died half way round the world/in horrible conditions ... and ... I don't 
think we can break faith with those that we left behind ... and it isn't just us ... it's the nation./I've had 6o years that they haven't had, haven't I? ... and I feel/ quite emotional about that.

FNK had found that communication in later life with members of the public was a positive and reconciliatory experience. He explained, 'I spoke to a meeting once and it seemed to go down extremely well ... and the pattern was really just simply to talk about ... what one had done ... and the sort of things that one had to face up to'. On the other hand, both ET and FNK saw the media's contributions as negative. FNK expressed concern for currently-serving troops :

I just don't like the way the media just blows everything up ... I get very worked up about that ... and I don't think they are contributing really ... to the sort of things you wanted to know from me.

\section{The incoherent narratives}

\section{Perceptions of war experience}

The themes that were distinctive to the five incoherent narratives related to the re-triggering of war memories in later life or their presence throughout life. In the following extract, BD explained how a chance meeting with a comrade only a few years before the interview had triggered traumatic memories, since when he had experienced nightmares every night:

But having ... sunk ... in the subconscious ... a terrible event/he started talking about (it)/man I cursed him when I had the first nightmare ... well, it was that very night ... got home ... went to bed ... and I wake up in a sweat ... and I'm right back there with it all again ... it was so life-like/I mean it's all those years ago ... nothing's faded ... even the smell I could smell.

These veterans had mixed perceptions of their war experiences but some mentioned no positive outcomes. XT said, for example, 'I don't think so ... it may have benefited some people ... but I don't think it did me'. Apart from traumatic battle experiences, some also spoke of other severe personal discomforts and difficulties during their active service. BD recollected that:

It wasn't always ... easy ... when you were working in jungle conditions ... I found that ... the humidity ... the climate ... was the worst possible ... enemy/ just a ... relentless war against ... insects ... dampness ... and ... fungus/was terrible ... for us young lads.

\section{Comradeship}

As with the other veterans, comradeship during the war was described positively and as important and there were similar references to lack of 
communication and the avoidance of others. EU associated the lack of communication with the absence of empathetic colleagues:

Well, I mean, most of the people I was with ... had the same kind of experience ... so ... [KB: Did you talk to each other whilst you were serving?]/ We had I think .... five or six Brits ... with 3 oo Indians ... and ... you ... were very much on your own. ... So there wasn't anybody to talk to anyway.

Nor was communication evident after the years of service. When it had occurred for EU, it was with younger veterans and he found the exchanges unsatisfactory because they had no shared memories. He elaborated in this way:

The only time I talk about it is when I go to my Royal Signals dos ... and there's/ three or four of us who were serving before the war... the rest were all much later ... they're ex-National Service men ... they're ex-Korean War/they respect us for what we did when we were in ... but ... there isn't a lot of talk to each other about matters of joint interest.

Contrasting with the uniformly positive comments about the veterans' associations in the coherent and reconciled narratives, these veterans gave mixed assessments. One observation was that associations were important but unavailable. BD explained how he and two comrades set up a local branch of the Royal British Legion, but shortly after his comrades died and he was unable to run the branch himself, and continued that he:

'had to wind up ... no one was prepared to step in and help ... and I wasn't prepared to do it all by myself ... so ... it wound up/which didn't help me at all'.

\section{Family support}

In the incoherent narratives, family interactions were described negatively, both those immediately after service and those in later life, and there were references to a lack of understanding from family members. JI attributed this to his wife's age: 'my wife of course is much younger than I ... she was a school girl during the war ... and ... it doesn't mean the same to her/it doesn't have the same ... impact, I suppose'. Unlike the veterans with coherent narratives, non-communication was reported throughout life with family members. During the years immediately after service, this was because returning veterans were encouraged to forget their war experiences and rebuild their civilian lives. When XT was asked if he talked about his war memories with his family, he explained, 'No ... because ... you're told to forget it, aren't you?' Unlike the veterans with reconciled narratives, however, avoidance and absence of communication had continued in later life, and was put down to perceived boredom and lack of interest. EU's remarks were particularly inconsistent. 
During the interview, he laughed but the underlying emotion was negative and the interviewer's reflective notes suggested he was saddened by this situation. His words were:

My children don't know ... I mean, they're old ... my daughter's 56 ... I should think it's more a question of, you know, when you start talking about that ... you see them falling asleep ... so it isn't a matter that comes up (laughs).

Finally, these veterans did not communicate when they returned home because they did not want to worry their family members or burden them with their experiences. JI recollected that he 'didn't want to worry them ... but ... they were very relieved of course'.

\section{Societal support}

Perceptions of societal opinion and support were negative. In the following example, WU described a negative interaction with a civilian after service, and implied that such interactions were common:

By accident one time when I was coming out ... of a public toilet ... I collided with a young man ... he said to me ... 'you silly old bastard, if I had my way, you wouldn't last five minutes, Dad.' ... A great surge of anger went through me. I could've punched a hole right in his head/to talk to me like that/I just fought a war to give him the freedom to say that to me, hadn't I? ... So I hated people./I couldn't get on with civilian life.

When these veterans had societal support, there were contradictions in what it meant to them. Speaking of such support, JI said, 'I don't say that it's important $\ldots$ but it's very ... gratifying ... I don't seek it'. He had also experienced instances of speaking to the public about his experiences but questioned its usefulness: ' I do give talks/try and explain ... and ... people try and understand ... but they can never really understand'.

The theme of commemoration was described with mixed valence by the veterans. In the following quote, $\mathrm{BD}$ explained that commemoration was a negative event for him. He believed that the public perception of VJ-Day (Victory in Japan) was less positive than that of VE-Day (Victory in Europe). BD appeared to believe that the British public were ashamed of Far East veterans, which made him angry:

And what was worse that no one gives a damn about you ... no one gives a damn ... and even now ... if you notice ... the last VJ celebration ... Prince Charles ... takes the Cenotaph ... and ... not even (Prime Minister) Blair turned up ... representing the Government/but when it was VE celebrations back in ... back in June ... it was the Queen was there ... and Blair was there/they're still ashamed of us.... I don't know why ... but I think we did a great job out there ... under terrible conditions ... terrible conditions. 
Finally, media representations were perceived to be negative because they failed to portray the reality of war. This reinforced the belief that the public do not and cannot understand war, which produced the feeling that society is unsympathetic. As WU explained:

So many war stories ... thousands of them on the telly. / Hollywood are making ... millions out of it all, aren't they?/But they're not putting it over the way it really is, you know ... you don't get the emotion ... the anxiety ... the gut feeling.

\section{Summary and discussion}

\section{Perceptions of war experience}

Veterans with coherent narratives appeared to perceive their war experience positively and described beneficial outcomes in their post-war lives. In comparison, veterans with reconciled and incoherent narratives reported negative experiences and few, if any, positive outcomes, and some reported negative post-war outcomes. Despite this, the war experiences of the three groups did not manifestly differ. It may be because the veterans with coherent narratives had found meaning in their war experiences and identified positive outcomes that they appeared not to have been troubled by their memories, an interpretation reached previously by Elder and his colleagues (Elder ig86; Elder, Gimbel and Ivie I99I). Research suggests that veterans who perceive gains that they attribute to their armed-service, such as maturity and preparation for future employment, suffer less psychological distress after service.

\section{Comradeship and family support}

A veteran's ability to find meaning in events, or to avoid confronting memories, is intricately linked to the social support they receive (Cohen and Wills I985). This study has provided interesting evidence of the different patterns that promote coherence. The interviews revealed that comrades and family did support processing and/or avoidance, but there was little evidence of the distinction suggested by Hunt and Robbins (200I) - they found that WWII and Korean War veterans processed memories with comrades, whilst family members supported avoidance. Among our informants, veterans with coherent narratives reported no real need to communicate, but had talked to family members about their experiences. Veterans with reconciled narratives reported that they had been encouraged to forget their war experience in earlier life. This had changed in later life, with communication taking place in a supportive 
family environment. Given the age of the veterans, comrades may not have been available for communication. As found by Hunt and Robbins (200I), some veterans with incoherent narratives had communicated with comrades but found the exchanges unsatisfactory. It seemed less that the veterans that we interviewed wanted to avoid talking about their experiences than that they were prevented from communicating with comrades and family members because of perceptions of boredom, lack of understanding and few opportunities.

\section{Societal support}

Variations in their perception of societal support clearly differentiated the veterans. Those with coherent and reconciled narratives by and large reported positive interactions with members of society and positive experiences of commemoration, but those with incoherent narratives described a feeling of being negatively perceived and misunderstood. The contrast is consistent with a previous finding that a supportive environment allows veterans to find meaning in experiences, particularly if the societal discourse is congruent with the individual's narrative (Davies 200 ; Hautamäki and Coleman 200I). Additionally, the themes also highlight the importance of commemoration in helping veterans cope with their experiences (Barron, Davies and Wiggins 2008).

\section{Reflections}

This study has explored the types of social support experienced by veterans with coherent, reconciled and incoherent narratives. Unlike previous research, the two-level narrative analysis was able to explore the different patterns of social support by different levels of coherence. Thematic analysis of the narrative content confirmed that comradeship, family support and societal support were important resources for these veterans. Our findings contest, however, the established understanding concerning the use of comradeship and family support: this may reflect differences among various samples or the use of the two-level analysis which allowed differences between experiences of social support to be explored across levels of narrative coherence. Such an approach may have revealed subtle nuances not detected by previous research.

The new findings contribute to our understanding of how it is that some veterans are able to communicate with family members and achieve reconciliation earlier in life, before critical resources such as cognitive ability, social networks and physical health diminish (Baltes and Lang 1997). Since this study has examined social support experiences throughout the 
lifespan, the possible reasons for unreconciled memories were highlighted by the veterans and the investigators, and possible ways of aiding processing were identified. For some, reconciliation did occur in later life, but this was achieved by communicating with family members in a positive environment. Veterans with incoherent narratives implied the need to manage memories but suggested that resources to support this were absent. We have examined the types of social support experienced by veterans that differed in their narrative coherence: the relationships we have described are postulates and no more than clues regarding the role that social support plays in reconciling and managing war memories. Given the nature of the sample and data, strictly no inferences regarding causality can be proposed.

Readers should also consider whether the young female interviewer influenced the research process. One might expect machismo to have affected disclosure, but the veterans spoke frankly and with great subtlety about their war experiences and their subsequent attempts to cope. Perhaps the presence of a young female interviewer actually broke down barriers and allowed the veterans to speak honestly and without fear of judgement (Gubrium and Holstein 200I). It might also be argued that the sample was self-selecting and biased. Whilst difficult to avoid in qualitative research, the method's strength is the ability to learn about the lives of individuals who are willing to share their experiences. Among the informants were veterans who had coped with experiences in different ways, and they were diverse. Future research would usefully explore the social support experiences of veterans of different life stages in order to understand these processes throughout the lifespan, and to determine if and how memories can be reconciled earlier in life.

\section{Conclusions}

Using two-level analysis, a theoretical model of social support and narrative (in)coherence throughout the lifespan has been formulated. A therapeutic intervention might be developed and evaluated from the findings, despite the concern that talking about traumatic memories can exacerbate symptoms. Perhaps the key requirement is to support veterans to talk about their experiences in a natural setting by drawing upon their informal supporters to help them find meaning in their experiences. The main difference between those with coherent or reconciled narratives and those with incoherent narratives was that they had a supportive personal and societal background that provided opportunities for communication. Such opportunities should be available to veterans of all ages. 


\section{Acknowledgements}

The authors are very grateful to the veterans who agreed to be interviewed for this research and to provide glimpses into such personal aspects of their lives. Thanks also to the organisations that helped to recruit our informants. The study was funded by the UK Economic and Social Research Council (award PTA-ozo2003-00319).

\section{NOTE}

I The study was approved by the University of Southampton Research Ethics Committee. Consideration was given to the effects of the veterans' participation and potential detrimental outcomes. They were given detailed information about the study and assured that any information provided would be anonymous, and that they could withdraw at any time. All were required to provide informed consent, debriefed and given the contact details of the Royal British Legion, and Combat Stress (the ex-services mental welfare society) after participating. Phone calls were made a week after the interview to assess the veterans' wellbeing and where necessary to provide additional contacts and advice.

\section{References}

Androutsopoulou, A., Thanopoulou, K., Economou, E. and Bafti, T. 2004. Forming criteria for assessing the coherence of clients' life stories: a narrative study. Fournal of Family Therapy, 26, 4, 384-406.

Baerger, D. R. and McAdams, D. P. I999. Life story coherence and its relation to psychological well-being. Narrative Inquiry, 9, I, 69-96.

Baltes, M. M. and Lang, F. R. 1997. Everyday functioning and successful aging: the impact of resources. Psychology and Aging, I 2, 3, 433-43.

Barron, D. S., Davies, S. P. and Wiggins, R. D. 2008. Social integration, a sense of belonging and the Cenotaph Service: old soldiers reminisce about remembrance. Aging and Mental Health, I 2, 4, 509-I6.

Brewin, C. R. 200I. A cognitive neuroscience account of posttraumatic stress disorder and its treatment. Behaviour Research and Therapy, 39, 4, 373-93.

Brewin, C. R., Dalgleish, T. and Joseph, S. I996. A dual representation theory of posttraumatic stress disorder. Psychological Review, 103, 4, 670-86.

Bruner, J. 1986. Actual Minds, Possible Worlds. Harvard University Press, Cambridge, Massachusetts.

Burnell, K. J., Coleman, P. G. and Hunt, N. $2006 a$. Falklands War veterans' perceptions of social support and the reconciliation of traumatic memories. Aging and Mental Health, I о, $3,282-9$.

Burnell, K. J., Hunt, N. and Coleman, P. G. 2006 b. Using narrative analysis to investigate the role of social support in the reconciliation of traumatic war memories. Health Psychology Update, I5, 3, 37-9.

Butler, R. N. I963. The life review: an interpretation of reminiscence in the aged. Psychiatry, 26, I, 65-76.

Chase, S. E. 2008. Narrative inquiry: multiple lenses, approaches, voices. In Denzin, N. K. and Lincoln, Y. S. (eds), Collecting and Interpreting Qualitative Materials. Sage, Thousand Oaks, California, 57-94. 
Cohen, S. and Wills, T. A. I985. Stress, social support, and the buffering hypothesis. Psychological Bulletin, 98, 2, 310-57.

Coleman, P. G. 1999. Creating a life story: the task of reconciliation. The Gerontologist, 39, 2, I33-9.

Creamer, M., Burgess, P. and Pattison, P. 1992. Reaction to trauma: a cognitive processing model. Fournal of Abnormal Psychology, ror, 3, 452-9.

Davies, S. 200I. The long-term psychological effects of traumatic wartime experiences on older adults. Aging and Mental Health, 5, 2, 99-103.

Dirkzwager, A. J. E., Bramsen, I. and van der Ploeg, H. M. 2003. Social support, coping, life events, and posttraumatic stress symptoms among former peacekeepers: a prospective study. Personality and Individual Differences, 34, 8, I545-59.

Elder, G. H. I986. Military times and turning points in men's lives. Developmental Psychology, 22, 2, 233-45.

Elder, G. H., Gimbel, C. and Ivie, R. I99I. Turning points in life: the case of military service and war. Military Psychology, 3, 4, 215-3I.

Foa, E. B., Molner, C. and Cashman, L. 1995. Change in rape narratives during exposure therapy for posttraumatic stress disorder. Fournal of Traumatic Stress, 8, 4, 675-9o.

Gubrium, J. F. and Holstein, J. A. 200I. Handbook of Interview Research: Context and Method. Sage, Thousand Oaks, California.

Habermas, T. and Bluck, S. 2000. Getting a life: the emergence of the life story in adolescence. Psychological Bulletin, 1 26, 5, 748-69.

Halbwachs, M. 1992. On Collective Memory. University of Chicago Press, Chicago.

Hautamäki, A. and Coleman, P. G. 20or. Explanation for low prevalence of PTSD among older Finnish war veterans: social solidarity and continued significance given to wartime sufferings. Aging and Mental Health, 5, 2, 165-74.

Hunt, N. and McHale, S. 2008. Memory and meaning: individual and social aspects of memory narratives. Fournal of Loss and Trauma, $\mathbf{1} 3, \mathbf{I}, 4^{2-5}$.

Hunt, N. and Robbins, I. 200I. World War II veterans, social support, and veterans' associations. Aging and Mental Health, 5, 2, I75-82.

Janet, P. 1909. Les Nervoses [Neuroses]. Flammarion, Paris.

Janoff-Bullman, R. 1992. Shattered Assumptions: Towards a New Psychology of Trauma. Free Press, New York.

Joffe, H. and Yardley, L. 2004. Content and thematic analysis. In Marks, D. F. and Yardley, L. (eds), Research Methods for Clinical and Health Psychology. Sage, London, $5^{6-68 .}$

Kaspersen, M., Matthiesen, S. B. and Gotestam, K. G. 2003. Social network as a moderator in the relation between trauma exposure and trauma reaction: a survey among UN soldiers and relief workers. Scandinavian Fournal of Psychology, 44, 5, 4I5-23.

King, L. A., King, D. W., Fairbank, J. A., Keane, T. M. and Adams, G. A. 1998. Resilience-recovery factors in post-traumatic stress disorder among female and male Vietnam veterans: hardiness, post-war social support, and additional stressful life events. Journal of Personality and Social Psychology, 74, 2, 420-34.

Linde, C. I993. Life Stories: The Creation of Coherence. Oxford University Press, New York.

McAdams, D. P. 2001. The psychology of life stories. Review of General Psychology, 66, 2, II $25-46$.

McFarlane, A. C. I992. Avoidance and intrusion in post-traumatic stress disorder. Fournal of Nervous and Mental Disease, r8o, 7, 439-45.

Murray, M. 2003. Narrative psychology and narrative analysis. In Camic, P. M., Rhodes, J. E. and Yardley, L. (eds), Qualitative Research in Psychology: Expanding Perspectives in Methodology and Design. American Psychological Association, Washington DC, 95-112.

Neuner, F., Schauer, M., Klaschik, C., Karunakara, U. and Elbert, T. 2004. A comparison of narrative exposure therapy, supportive counselling, and psychoeducation for treating 
posttraumatic stress disorder in an African refugee settlement. Fournal of Consulting and Clinical Psychology, 72, 4, 579-87.

Polkinghorne, D. E. I988. Narrative Knowing and the Human Sciences. SUNY Press, Albany, New York.

Riessman, C. K. I993. Narrative Analysis. Sage, Thousand Oaks, California.

Riessman, C. K. 2002. Analysis of personal narratives. In Gubrium, J. F. and Holstein, J. A. (eds), Handbook of Interview Research. Sage, Thousand Oaks, California, 695-710.

Rose, S., Bisson, J., Churchill, R. and Wessely, S. 2007. Psychological debriefing for preventing post-traumatic stress disorder (PTSD) (review). Cochrane Database of Systematic Reviews, 2002, 2, CDooo56o. doi: I0.1002/14651858. CDooo560.

Smith, J. A. 1995. Semi-structured interviewing and qualitative analysis. In Smith, J. A., Harre, R. and Van Langenhove, L. (eds), Rethinking Methods in Psychology. Sage, London, $9^{-27 .}$

Solomon, Z., Mikulincer, M. and Avitzur, E. 1988. Coping, locus of control, social support, and combat-related posttraumatic stress disorder: a prospective study. Fournal of Personality and Social Psychology, 55, 2, 279-85.

van der Kolk, B. A. and Fisler, R. I995. Dissociation and the fragmentary nature of traumatic memories: overview and exploratory study. Fournal of Traumatic Stress, 8, 4, 505-25.

Wessely, S. and Deahl, M. 2003. Psychological debriefing is a waste of time. British fournal of Psychiatry, 183, I, I2-I4.

Wilkinson, S., Joffe, H. and Yardley, L. 2004. Qualitative data collection. In Marks, D. F. and Yardley, L. (eds), Research Methods for Clinical and Health Psychology. Sage, London, 39-55.

Zoellner, L. A., Alvarez-Conrad, J. and Foa, E. B. 2002. Peri-traumatic dissociative experiences, trauma narratives, and trauma pathology. Fournal of Traumatic Stress, I5, I, $49^{-57}$.

Address for correspondence:

Karen Burnell, Department of Mental Health Sciences, University

College London, 67-73 Riding House Street, ist floor Charles Bell House, London $\mathrm{W}_{\mathrm{I}} \mathrm{W} 7 \mathrm{EJ}$, UK.

E-mail: k.burnell@ucl.ac.uk 